\title{
Potencial de biocontrole de Trichoderma spp. contra Macrophomina phaseolina do Feijão-caupi
}

\author{
Biocontrol potential of Trichoderma spp. against \\ Macrophomina phaseolina from Cowpea
}

'Laboratôrio de Controle Biolōgico, Instituto Agronômico de Pernambuco, Avenida General San Martin, 1371 Bongi, CEP 50761-000, Recife, PE, Brasil ${ }^{2}$ Bolsista DCR/FACEPE-CNPq ${ }^{3}$ Departamento de Micologia, Universidade Federal de Pernambuco, Recife, PE, Brasil

4Programa de Pós-Graduação em Proteção de Plantas, Instituto Federal Goiano, Urutaí, Goiās, GO, Brasil

*autor correspondente 凶 lugoliveira@gmail.com

Luciana Gonçalves de Oliveira', ${ }^{1 *}$ (1) , Mayara Goes Kettner ${ }^{3}$, Maria Luiza de Souza Lima ${ }^{3}$, Emmanuelle Rodrigues Araújo' (D), Anderson Rodrigo da Silva ${ }^{4}$, Antonio Félix da Costa' (1)

RESUMO: O feijão-caupi possui grande importância socioeconômica por fazer parte do hábito alimentar da população e por ser uma das principais fontes de emprego e renda. As doenças estão entre os fatores limitantes da produtividade dessa cultura. Uma das principais enfermidades que acometem o feijão-caupi é causada pelo fungo Macrophomina phaseolina. Em busca de um desenvolvimento agrícola sustentável, o uso de agentes de controle biológico é considerado uma alternativa viável. Diante disso, o objetivo desta pesquisa foi avaliar o potencial de biocontrole in vitro e in vivo de $M$. phaseolina isolado de plantas do feijão-caupi por isolados de Trichoderma sp. Os bioensaios foram realizados no Instituto Agronômico de Pernambuco em 2017 e 2018. Para o bioensaio in vitro, foi realizado o teste de cultura pareada em placas de Petri utilizando sete isolados de Trichoderma no laboratório de Controle Biológico. Para o bioensaio in vivo, realizado em casa de vegetação do IPA, foram avaliados cinco isolados de Trichoderma mais três testemunhas (Testemunha positiva $=$ apenas com Trichoderma, Testemunha negativa $=$ só com o patógeno e Testemunha absoluta $=$ sem patógeno e sem o biocontrolador), em delineamento experimental inteiramente casualizado com oito tratamentos e três repetições, sendo vasos contendo três plantas, a unidade experimental. De acordo com os resultados in vitro, todos os isolados de Trichoderma avaliados apresentaram atividade antagônica sobre o crescimento micelial de $M$. phaseolina. E na avaliação in vivo, em casa de vegetação, os cinco isolados testados apresentaram atividade biocontroladora sobre o patógeno, indicando que isolados de Trichoderma sp. possuem potencial para o manejo da podridão cinzenta do caule.

Palavras-chave: Antagonismo, controle biológico, podridão cinzenta do caule, Vigna unguiculata.
ABSTRACT: Cowpea has great socioeconomic importance as part of the population's eating habits, and for being one of the main sources of income and employment. Diseases are among the limiting factors in cowpea productivity. The soil fungi Macrophomina phaseolina is one of the most important diseases that affect cowpea. However, an alternative for this pathogen is a sustainable agricultural development; the use of biological control agents is considered a viable alternative. Therefore, this research aimed to evaluate the biocontrol potential in vivo and in vitro of Macrophomina phaseolina isolated from cowpea plants by Trichoderma sp. The bioassays were carried out at the Agronomic Institute of Pernambuco in 2017 and 2018, in a paired culture test with seven Trichoderma strains in vitro in the Biological Control Laboratory using the dual culture method. For the in vivo bioassay, carried out in the IPA greenhouse, five Trichoderma isolates plus three controls were evaluated (positive control = only with Trichoderma, negative control = only with the pathogen and absolute control $=$ no pathogen and no biocontroller). in a completely randomized experimental design with 8 treatments and three replications, with pots containing 3 plants, the experimental unit. According to the in vitro results, all Trichoderma isolates evaluated presented antagonistic activity on the mycelial growth of M. phaseolina. While in the in vivo evaluation, in a greenhouse, the five tested isolates showed biocontrolling activity on the pathogen, indicating that Trichoderma sp. have potential for the management of charcoal root rot.

Keywords: Antagonism, biological control, charcoal root rot, Vigna unguiculata. 


\section{Introdução}

O feijão-caupi (Vigna unguiculata (L.) Walp.), também conhecido popularmente por feijão-de-corda, é uma cultura importante para as populações de países tropicais e subtropicais, sendo considerado uma das principais fontes proteicas da alimentação humana, além de possuir baixo custo de produção (RAMOS et al., 2012; ALMEIDA et al., 2010). No Brasil, o feijão-caupi possui grande importância devido à alta demanda consumidora, por fazer parte do hábito alimentar da população e por ser uma das principais fontes de emprego e renda (FREIRE et al., 2011). Esse feijão possui maior rusticidade e resistência ao estresse hídrico, adaptando-se bem às condições de menor disponibilidade de água, favorecendo, assim, o seu cultivo na região Nordeste (BRASIL, 2021). Nessa região, a produção na segunda safra de 2020 foi estimada em 295,9 mil toneladas, e os maiores estados produtores são Ceará, Piauí e Pernambuco (BRASIL, 2020). Contudo, apesar de ser cultivado em larga escala, os níveis de produtividade da cultura são inferiores ao seu potencial genético e produtivo (ROSOLEM, 1987; SILVA et al., 2018).

As doenças estão entre os fatores limitantes da produtividade do feijão-caupi, afetando negativamente a quantidade e qualidade da produção. Uma das principais enfermidades que acometem o feijão-caupi é causada pelo fungo Macrophomina phaseolina. Esse fungo é um fitopatógeno polífago de solo, causador da podridão cinzenta do caule, que ataca mais de 680 espécies de plantas (FARR; ROSSMAN, 2021), como o algodão (Gossypium hirsutum $L$.), feijão-comum (Phaseolus vulgaris $L$.), gergelim (Sesamum indicum L.), girassol (Helianthus annuus L.), melão (Cucumis melo L.), milho (Zea mays L.), soja [Glycine max (L.) Merrill] (GUPTA; SHARMA; RAMTEKE, 2012; ISLAM et al., 2012; KAUR et al., 2012).

A podridão cinzenta do caule é uma doença importante no Nordeste do Brasil, onde as lavouras estão sujeitas a estresses, principalmente hídrico. Seu agente etiológico, M. phaseolina (Tassi) Goldi, é um habitante natural do solo, de grande variabilidade patogênica e alta capacidade de sobrevivência em condições adversas. Os prejuízos à cultura do feijão são determinados tanto pelo baixo desempenho produtivo das plantas e da baixa qualidade da semente produzida, quanto ao vigor e sanidade, morte de sementes e plântulas, cancro e lesões cinzentas no caule e pela diminuição do estande (PEDROSO, 2012). Isso acontece porque as condições propícias para o desenvolvimento de $M$. phaseolina são temperaturas entre $28-35^{\circ} \mathrm{C}$, ocorrendo danos ainda maiores em clima seco e altas temperaturas. Esse patógeno sobrevive no solo e em restos culturais, e é transmitido por sementes (BORGES et al., 2015; GODOY et al., 2016). Para o semiárido nordestino, essa doença se torna ainda mais importante, pois as condições climáticas favorecem o estabelecimento do fungo, somado ainda aos baixos níveis de tecnologia de produção que favorecem seu desenvolvimento e sobrevivência.

O método mais utilizado para controle de doenças no campo ainda é o uso de agroquímicos, porém o uso crescente e indiscriminado desses produtos tem ocasionado riscos ambientais, à saúde dos agricultores, trabalhadores e consumidores. Em busca de um desenvolvimento agrícola sustentável, o uso de agentes de controle biológico é considerado uma alternativa viável. Diante disso, os micro-organismos antagônicos utilizados para o biocontrole podem proporcionar excelentes níveis de controle a médio e longo prazo (KIM et al., 2008). Dentre eles, o gênero Trichoderma é o mais estudado, sendo utilizado no biocontrole de diversos patógenos que habitam o solo (KHAN et al., 2019). $\mathrm{O}$ interesse por este fungo deve-se a diversos mecanismos de ação como produção de antibióticos voláteis e não voláteis, competição por espaços e nutrientes, atividade enzimática hidrolítica e parasitismo (BRITO et al., 2014). Além disso, esses micro-organismos não são tóxicos ao homem e a animais (MERTZ et al., 2009).

Em vista disso, este trabalho teve como objetivo avaliar o potencial de biocontrole in vitro e in vivo de M. phaseolina, isolados de plantas do feijão-caupi, por isolados de Trichoderma sp.

\section{Material e Métodos}

Isolamento e identificação dos fungos Trichoderma e Macrophomina phaseolina: as espécies de Trichoderma foram coletadas de solos com plantios de feijão comum e de feijão-caupi nos municípios de Belém de São Francisco, Chã Grande e Arcoverde (Pernambuco). Para o isolamento de $M$. phaseolina, plantas com sintomas da doença podridão cinzenta do caule foram coletadas no município de Belém de São Francisco, em áreas produtoras de feijão-caupi e, posteriormente, levadas para o laboratório de Controle Biológico, na Sede do Instituto Agronômico de Pernambuco (IPA), Recife - PE, sendo realizados o isolamento e a identificação dos fungos, segundo a metodologia proposta por Menezes e Silva (1997).

Biocontrole com Trichoderma spp. in vitro: o bioensaio foi realizado no Laboratório de Controle Biológico do IPA, no ano de 2017. Para isso, foi utilizado o método de cultura pareada para verificar o potencial antagonista in vitro dos isolados de Trichoderma sobre M. phaseolina. Discos de micélio de $M$. phaseolina e do antagonista (Trichoderma sp.) com $5 \mathrm{~mm}$ de diâmetro foram retirados de colônias com três dias de cultivo e depositados, simultaneamente, em extremidades opostas de placas de Petri contendo meio BDA (Batata-Dextrose-Ágar) solidificado. As placas foram mantidas à temperatura de $\pm 27^{\circ} \mathrm{C}$ (em câmara tipo BOD). Após sete dias de cultivo, foi avaliado o crescimento micelial de ambos os fungos. A avaliação do potencial antagônico dos isolados de Trichoderma foi realizada com base na escala de Bell et al. (1982): Classe 1: Trichoderma cresce sobre o patógeno e ocupa toda a superfície da placa; Classe 2: Trichoderma cresce sobre pelo menos $2 / 3$ da superfície da placa; Classe 3: Trichoderma e patógeno ocupam cada um aproximadamente metade da superfície da placa e nenhum deles parece se sobressair; Classe 4: Patógeno cresce pelo menos 2/3 da superfície da placa; Classe 5: Trichoderma não cresce e o patógeno ocupa toda a superfície da placa.

Biocontrole com Trichoderma spp. in vivo: o experimento foi realizado em casa de vegetação, localizada no Instituto Agronômico de Pernambuco (IPA), em 2018. Foi utilizado solo autoclavado $\left(120^{\circ} \mathrm{C} / 1 \mathrm{~h}\right)$ e foram utilizadas três sementes por vaso, com três repetições para cada tratamento, sendo realizado um único bioensaio. Para a produção do inóculo 
de M. phaseolina, foi utilizada a metodologia adaptada para infecção proposta por Lima et al. (2013), em que o patógeno foi cultivado em placa de Petri contendo grãos de sorgo, e posteriormente mantido em BOD a $27^{\circ} \mathrm{C}$. Em seguida, para a infestação do solo, foram utilizados três grãos de sorgo infestados com o patógeno para cada semente. Para a inoculação com isolados de Trichoderma sp. foi utilizada uma solução com $1 \times 10^{7}$ conídios $/ \mathrm{ml}$ de Trichoderma, sendo inoculada a semente no momento do plantio. Após 28 dias foram realizadas avaliações, sendo as plantas removidas para observação dos sintomas causados pelo patógeno e determinada a porcentagem dos sintomas da doença.

Análise de dados: para o experimento in vivo, o delineamento experimental foi o inteiramente casualizado, com tratamentos constituídos por sete isolados de Trichoderma e três testemunhas (Testemunha positiva $=$ apenas com Trichoderma, Testemunha negativa $=$ só com o patógeno e Testemunha absoluta $=$ sem patógeno e sem o biocontrolador), com três repetições. Os dados foram submetidos ao teste não paramétrico de Kruskal-Wallis. Os tratamentos foram comparados aos pares pela versão não paramétrica do teste LSD de Fisher a 5\% de significância, com base nas somas dos ranks. As análises estatísticas foram executadas com o pacote agricolae (MENDIBURU, 2021) versão no Software R.

\section{Resultados e Discussão}

O potencial antagônico de Trichoderma in vitro sobre M. phaseolina foi observado em todos os isolados testados, enquadrando-se todos na nota 2 , em que o fungo antagonista cresce sobre pelo menos $2 / 3$ da superfície da placa, segundo a classificação de Bell et al. (1982). A capacidade do Trichoderma sp. em inibir o desenvolvimento de outros fungos é caracterizada, dentre outras estratégias, como antibiose, pela síntese e liberação de moléculas com alto e baixo peso molecular que são responsáveis pela atividade antifúngica que impede o crescimento do fitopatógeno (CUBILLA-RÍOS et al., 2019).

Os resultados do presente estudo corroboram com os dados encontrados por Parmar e Patel (2020), os quais afirmam que cinco isolados de Trichoderma sp. testados tiveram um efeito antagônico significativo sobre o crescimento micelial de $M$. phaseolina em soja. Hewedy et al. (2020) também observaram que todas as cepas de Trichoderma inibiram consistentemente M. phaseolina à medida que cresciam superficialmente junto com sua colônia e inibiram seu crescimento em porcentagem que variou de $64,05 \%$ a $72,97 \%$.

Estudos in vitro com outros fitopatógenos como Fusarium spp., Ascochyta spp., Pyrenophora teres e Sclerotinia sclerotiorum, utilizando Trichoderma sp. como biocontrolador, mostraram Trichoderma como um antagonista eficiente, inibindo o crescimento micelial dos fitopatógenos em mais de 50\% (TANCIC-ZIVANOV et al., 2017). Esses testes in vitro são importantes no processo de seleção de isolados para o biocontrole, pois fornecem informações em condições controladas sobre a eficiência e a variabilidade dos isolados quanto à capacidade de colonização das estruturas do patógeno e o potencial de hiperparasitismo e competição por espaço e nutrientes, bem como a suscetibilidade de patógenos aos respectivos agentes (NASCIMENTO et al., 2016).

Quanto ao biocontrole in vivo dos isolados de Trichoderma, quatro isolados comportaram-se como controladores e bioprotetores das sementes, quando comparados ao controle (sem antagonista), variando o percentual de sobrevivência das plantas. $\mathrm{O}$ teste de Kruskal-Wallis apresentou resultado significativo $\left(\mathrm{X}^{2}=20.4\right.$, p-valor $=0.0156)$. Na Tabela 1 encontram-se as médias e os sintomas da doença (\%) e o resumo do teste LSD de Fisher.

Os isolados de Trichoderma BSF 3, Trichoderma Chã Grande 15.2, Trichoderma Chã Grande 16.1 e Trichoderma Arcoverde 5.6 foram os mais promissores, não permitindo o desenvolvendo da doença causada por Macrophomina phaseolina, demonstrando ser efetivos no biocontrole da podridão cinzenta do caule. Em estudos semelhantes realizados por Khaledi e Taheri (2016), a ação biocontroladora foi observada em 11 isolados de Trichoderma sp. testados, no entanto, apenas dois mostraram uma redução significativa dos sintomas da doença causada por M. phaseolina. Por sua vez, Khalili et al. (2017) e Iqbal e Mukhtar (2020) evidenciaram a ação biocontroladora de Trichoderma sobre esse mesmo patógeno. Os outros três isolados de Trichoderma apresentaram variações na eficácia do biocontrole, em que algumas plantas apresentaram sintomas da podridão cinzenta do caule. $\mathrm{O}$ isolado de Trichoderma Chã Grande 13.1 apresentou maior percentual dos sintomas $(22,2 \%)$, porém não mostrou diferença estatística significativa entre os dois isolados de Trichoderma asperellum, com 11,1\% dos sintomas da doença. As variações entre Trichoderma spp. em sua capacidade de controlar o crescimento de fitopatógenos também foram relatadas em outros estudos (UPMANYU et al., 2002; SINGH et al., 2008; IQBAL; MUKHTAR, 2020).

As diferentes espécies de Trichoderma se mostraram controladoras de muitos patógenos habitantes do solo, incluindo Rhizoctonia solani, Pythium ultimum, Fusarium moniliforme, F. oxysporum e Sclerotium rolfsii (GHAZANFAR et al., 2018). Segundo Khan et al. (2019), Trichoderma sp. tem eficácia maior

Tabela 1. Teste de Kruskal-Wallis contendo as médias e os sintomas da doença em porcentagem, juntamente com o teste LSD de Fisher.

\begin{tabular}{lcc}
\hline \multicolumn{1}{c}{ Tratamento } & Sintomas da doença (\%) & LSD \\
\hline Testemunha absoluta & 0 & C \\
Testemunha negativa & 100 & A \\
Testemunha positiva & 0 & C \\
Trichoderma (Chã Grande 16.1) & 0 & C \\
Trichoderma asperellum (1) & 11.1 & Bc \\
Trichoderma (Chã Grande 15.2) & 0 & C \\
Trichoderma (Arcoverde 5.6) & 0 & C \\
Trichoderma (BSF 3) & 0 & C \\
Trichoderma (Chã Grande 13.1) & 22.2 & B \\
Trichoderma asperellum (2) & 11.1 & Bc \\
\hline
\end{tabular}

Testemunha absoluta $=$ sem patógeno e sem o biocontrolador; Testemunha negativa $=$ só com o patógeno; Testemunha positiva $=$ apenas $\mathrm{com}$ Trichoderma. 
que o tratamento com o químico Carbendazim no controle da severidade da podridão radicular.

Segundo Vinale et al. (2008), o biocontrole exercido pelo fungo Trichoderma está relacionado com a produção de vários metabólitos, enzimas e por mecanismos como competição por nutrientes, o que pode ter contribuído com as diferentes respostas do presente estudo em relação a M. phaseolina. As diferenças podem estar relacionadas com as condições bióticas e abióticas do solo, o que pode levar à variação do nível de controle biológico de um patógeno (ISAIAS et al., 2014). Pesquisas demonstram que a eficácia relativa do controle da doença exercido por Trichoderma spp. varia com a cepa, o patógeno-alvo, as espécies de cultivo e o clima (MOHIDDIN et al., 2010).

\section{Conclusão}

Os isolados de Trichoderma utilizados neste estudo possuem potencial para manejo da podridão cinzenta do caule, controlando Macrophomina phaseolina.

Fica evidente que o uso de biocontroladores antagonistas é uma alternativa no controle de doenças em feijão-caupi.

\section{Agradecimentos}

À FACEPE - Fundação de Amparo a Ciência e Tecnologia do Estado de Pernambuco pela concessão de bolsa de pesquisa ao primeiro autor (DCR 007-5.01/16 e BCT 0098-5.01/16).

\section{Referências}

Almeida, A. L. G. et al. Produtividade do feijão-caupi cv BR 17 Gurguéia inoculado com bactérias diazotróficas simbióticas no Piauí. Agrária, Recife, v. 5, n. 3, p. 364-369, 2010.

Bell, D. K.; Wells, H. D.; Markham, C. R. In vitro antagonism of Trichoderma species against six fungal plant pathogens. Journal of Phytopathology, Berlin, v. 72, n. 4, p. 379-382, 1982.

Borges, E. P.; Andrade, D. F. A. A.; Borges, R. A. Doenças da soja e seu controle. In: BORGES, E. P. (Ed.). Pesquisa, tecnologia, e produtividade: soja/ milho 2014/2015. Chapadão do Sul: Fundação Chapadão, 2015. p. 96-108.

BRASIL. Acompanhamento da safra brasileira - Grãos. Safra 2020/21. V. 8 - N.1 Primeiro Levantamento. Brasília: Conab, 2021, p. 1-77. Disponível em: <https://www.conab.gov.br/info-agro/ safras/graos/boletim-da-safra-de-graos>. Acesso em: 08 mar. 2021.

BRASIL. Acompanhamento da safra brasileira - Grãos: Safra 2019/2020 - N. 12-Décimo segundo levantamento. Brasília: Conab, 2020, p. 1-68. Disponível em: <https://www.conab.gov.br/info-agro/ safras/graos/boletim-da-safra-de-graos>. Acesso em: 08 mar. 2021.

Brito, J. P. C. et al. Peptaibols from Trichoderma asperellum TR 356 strain isolated from Brazilian soil. SpringerPlus, Berlin, v. 3, n. 1, p. 600-610, 2014.

Cubilla-Ríos, A. A. et al. Antibiosis de proteínas y metabolitos en especies de Trichoderma contra aislamientos paraguayos de Macrophomina phaseolina. Agronomía Mesoamericana, San José, v. 30, n. 1, p. 63-77, 2019. http://dx.doi.org/10.15517/am.v30i1.34423.

Farr, D. F.; ROSSMAN, A.Y. Fungus-host distribution database. USDA - ARS. Disponível em:< https://nt.ars-grin.gov/fungaldatabases/>. Acesso em: 08 mar. 2021.
Freire, F. R. et al. Feijão-caupi no Brasil: produção, melhoramento genético, avanços e desafios. Teresina: Embrapa Meio-Norte, 2011. $84 \mathrm{p}$.

Ghazanfar, M. U. et al. Trichoderma as potential biocontrol agent, its exploitation in agriculture: a review. Journal of Plant Protection Research, Poznań, v. 2, p. 109-135, 2018.

Godoy, C. V. et al. Doenças da soja. In: AMORIM, L.; REZENDE, J. A. M. C.; BENJAMIM, A.; CAMARGO, L. E. A. (Ed.). Manual de fitopatologia: doenças de plantas cultivadas. Ouro Fino: Editora Agronômica Ceres Ltda, 2016. p. 657-676.

Gupta, G. K.; SHARMA, S. K.; RAMTEKE, R. Biology, epidemiology and management of the pathogenic fungus Macrophomina phaseolina (Tassi) Goid. with special reference to charcoal rot of soybean (Glycine max (L.) Merrill). Journal of Phytopathology, Berlin, v. 160, p. 167-180, 2012.

Hewedy, O. A. et al. Phylogenetic diversity of Trichoderma strains and their antagonistic potential against soil-borne pathogens under stress conditions. Biology, Basel, v. 9, p. 189, 2020.

Iqbal, U.; Mukhtar, T. Evaluation of biocontrol potential of seven indigenous Trichoderma species against charcoal rot causing fungus, Macrophomina phaseolina. Gesunde Pflanzen, Bonn, v. 72, p. 195-202, 2020.

Isaias, C. O. et al. Ação antagônica e de metabólitos bioativos de Trichoderma spp. contra os patógenos Sclerotium rolfsii e Verticillium dahliae. Summa Phytopathologica, Botucatu, v. 40, n. 1, p. 34-41, 2014.

Islam, M. S. et al. Tools to kill: genome of one of the most destructive plant pathogenic fungi Macrophomina phaseolina. BMC Genomics, London, v. 13, p. 493-509, 2012.

Kaur, S. et al. Emerging phytopathogen Macrophomina phaseolina: biology, economic importance and current diagnostic trends. Critical Reviews in Microbiology, London, v. 38, n. 2, p.136-151, 2012.

Khaledi, N.; Taheri, P. Biocontrol mechanisms of Trichoderma harzianum against soybean charcoal rot caused by Macrophomina phaseolina. Journal of Plant Protection Research, Poznań, v. 56 , n. 1, p. 21-31, 2016. http://dx.doi.org/10.1515/jppr-2016-0004.

Khalili, E. et al. Optimization of cultivation conditions in banana wastes for production of extracellular $\beta$-glucosidase by Trichoderma harzianum Rifai efficient for in vitro inhibition of Macrophomina faseolina. Biotechnology \& Biotechnological Equipment, London, v. 31, n. 5, p. 921-934, 2017.

Khan, M. R. et al. Management of root-rot disease complex of mungbean caused by Macrophomina phaseolina and Rhizoctonia solani through soil application of Trichoderma spp. Crop Protection, Guildford, v. 119, p. 24-29, 2019. http://dx.doi.org/10.1016/j.cropro.2019.01.014.

Kim, Y. C. et al. An effective biocontrol bioformulation against Phytophthora blight of pepper using growth mixtures of combined chitinolytic bacteria under different field conditions. European Journal of Plant Pathology, Amsterdam, v. 120, p. 373-382, 2008.

Lima, L. R. L. et al. Influência de metodologia de inoculação e da concentração de inóculo de Macrophomina phaseolina no desenvolvimento da podridão-cinzenta-do-caule em feijão-caupi. In: III CONGRESSO NACIONAL DE FEIJÃO-CAUPI. Anais... Recife: CONAC, 2013.

Mendiburu, F. Agricolae: Statistical Procedures for Agricultural Research - version 1.3.5. R-Project, 2021. Disponível em: $<$ https:// CRAN.R-project.org/package=agricolae $>$. Acesso em: 15 mar. 2021 .

Menezes, M.; Silva, D. M. W. Guia prático para isolamentos de fungo fitopatogênicos. Recife: UFRPE, 1997. 120p. 
Mertz, L. M.; Henning, F. A.; Zimmer, P. D. Bioprotetores e fungicidas químicos no tratamento de sementes de soja. Ciência Rural, Santa Maria, v. 39, n. 1, p. 13-18, 2009.

Mohiddin, F. A.; Khan, M. R.; Khan, S. M. Why Trichoderma is considered super hero (super fungus) against the evil parasites? European Journal of Plant Pathology, Amsterdam, v. 9, n. 3, p. 92-102, 2010.

Nascimento, S. R. C. et al. Sobrevivência de estrutura de resistência de Macrophomina phaseolina e Sclerotium rolfsii em solo tratado biologicamente. Revista Agro@mbiente online, Boa Vista, v. 10, n. 1, p. 50-56, 2016. http://dx.doi.org/10.18227/1982-8470ragro. v10i1.2947

Parmar, R. G.; Patel, P. S. Efficacy of bioagents against Macrophomina phaseolina causing root rot of soybean in vitro. Journal of Pharmacognosy and Phytochemistry, New Delhi, v. 9, n. SP6, p. 196-198, 2020.

Pedroso, C. Incidência, controle de doenças de feijão-vagem e anatomia e histoquímica de Phaseolus vulgaris e Vigna unguiculata resistentes e suscetíveis ao oídio (Erysiphe polygoni). $135 \mathrm{f}$. Tese (Doutorado em Fitopatologia)-Universidade de Brasília, Brasília, 2012.

Ramos, H. M. M. et al. Estratégias ótimas de irrigação do feijão-caupi para produção de grãos verdes. Pesquisa Agropecuária Brasileira, Brasília, v. 47, n. 2, p. 576-583, 2012.
Rosolem, C. Nutrição e adubação do feijoeiro. Piracicaba: Potafos, 1987. 93 p.

Silva, A. C. et al. Diagnóstico da produção de feijão-caupi no nordeste brasileiro. Revista da Universidade Vale do Rio Verde, Três Corações, v. 16, n. 2, p. 1-5, 2018.

Singh, S.; Chand, H.; Varma, P. K. Screening of bioagents against root rot of mung bean caused by Rhizoctonia solani. Legume Research, Haryana, v. 31, p. 75-76, 2008.

Tancic-Zivanov, S. et al. Efficacy of Trichoderma spp. against Common Fungal Pathogens. Ratarstvo i Povrtarstvo, Belgrade, v. 54, n. 3, p. 104-109, 2017. http://dx.doi.org/10.5937/ratpov54-14254.

Upmanyu, S.; Gupta, S. K.; Shyam, K. R. Innovative approaches for the management of root rot and web blight (Rhizoctonia solani) of french bean. Journal of Mycology and Plant Pathology, Udaipur, v. 32, p. 317-331, 2002.

Vinale, F. et al. Trichoderma-plant-pathogen interactions. Soil Biology \& Biochemistry, Amsterdam, v. 40, n. 1, p. 1-10, 2008. http:// dx.doi.org/10.1016/j.soilbio.2007.07.002. 